\title{
Association between XRCC1 and ERCC1 single-nucleotide polymorphisms and the efficacy of concurrent radiochemotherapy in patients with esophageal squamous cell carcinoma
}

\author{
XUE HUANG $^{1 *}$, CHANGMIN LIU $^{2 *}$, YAYUN CUI $^{3 *}$, HEPING ZHANG $^{1}$, \\ YONGPING LIU ${ }^{1}$, XIFA ZHOU ${ }^{1}$ and JUDONG LUO ${ }^{1}$ \\ ${ }^{1}$ Department of Radiation Oncology, Changzhou Tumor Hospital Affiliated to Soochow University, Changzhou, \\ Jiangsu 213001; ${ }^{2}$ Department of Oncology, Affiliated Hospital of Binzhou Medical College, Binzhou, Shandong 256603; \\ ${ }^{3}$ Department of Radiation Oncology, Anhui Provincial Hospital, Hefei, Anhui 230001, P.R. China
}

Received June 30, 2015; Accepted September 30, 2016

DOI: $10.3892 / \mathrm{ol} .2016 .5496$

\begin{abstract}
The aim of the present study was to investigate the association between single-nucleotide polymorphisms (SNPs) in X-ray repair cross-complementing 1-399 (XRCC1-399) or excision repair cross-complementation group 1-118 (ERCC1-118) and the short-term efficacy of radiochemotherapy, tumor metastasis and relapse, as well as the survival time in patients with esophageal squamous cell carcinoma (ESCC). TaqMan probe-based quantitative polymerase chain reaction (qPCR) was conducted to examine the levels of XRCC1-399 and ERCC1-118 SNPs in the peripheral blood of 50 patients with pathologically confirmed ESCC. In addition, the associations between different genotypes and short-term therapeutic efficacy [the complete remission (CR) rate], tumor metastasis and relapse, as well as the survival time following concurrent radiochemotherapy, were determined. A total of 50 ESCC patients who received concurrent radiochemotherapy were enrolled. It was found that the short-term therapeutic efficacy (CR rate) was higher in the group of patients carrying the homozygous mutation of XRCC1-399 (A/A genotype) than in the group of patients without the XRCC1-399 mutation $(\mathrm{G} / \mathrm{G}$ genotype). In addition, the $\mathrm{CR}$ rate was significantly increased in patients carrying one or two ERCC1-118 $\mathrm{C}$ alleles $(\mathrm{C} / \mathrm{C}$ or $\mathrm{C} / \mathrm{T}$ genotype) compared with patients lacking the $\mathrm{C}$ allele (T/T genotype). The differences were statistically significant
\end{abstract}

Correspondence to: Dr Xifa Zhou or Dr Judong Luo, Department of Radiation Oncology, Changzhou Tumor Hospital Affiliated to Soochow University, 68 Honghe Road, Changzhou, Jiangsu 213001, P.R. China

E-mail: zhouxifacz@sina.com

E-mail: judongluo@163.com

*Contributed equally

Key words: esophageal cancer, concurrent radiochemotherapy, single nucleotide polymorphism, X-ray cross-complementing group 1, excision repair cross-complementing group 1
(A/A vs. $\mathrm{G} / \mathrm{G}, \mathrm{P}=0.014$; TT vs. $\mathrm{C} / \mathrm{T}+\mathrm{C} / \mathrm{C}, \mathrm{P}=0.040$ ). During the follow-up period, the group of patients carrying the homozygous mutation of XRCC1-399 (A/A genotype) exhibited a markedly reduced risk of metastasis and relapse compared with the group of patients carrying non-mutated XRCC1-399 (G/G genotype; $\mathrm{P}=0.031$ ). By contrast, ERCC1-118 SNP was not associated with the risk of metastasis and recurrence ( $P>0.05)$. The combined results of univariate and multivariate Cox regression analysis showed that the SNP in ERCC1-118 was closely associated with survival time. The mean survival time was significantly prolonged in patients carrying 1 or $2 \mathrm{C}$ alleles $(\mathrm{C} / \mathrm{C}$ or $\mathrm{C} / \mathrm{T}$ genotype) compared with patients lacking the $\mathrm{C}$ allele (T/T genotype) [T/T vs. $\mathrm{C} / \mathrm{C}, \mathrm{HR}=12.96$, $95 \%$ confidence interval $(\mathrm{CI})=3.08-54.61, \mathrm{P}<0.001$; TT vs. $\mathrm{C} / \mathrm{T}+\mathrm{C} / \mathrm{C}, \mathrm{HR}=11.71,95 \% \mathrm{CI}=3.06-44.83, \mathrm{P}<0.001]$. However, XRCC1-399SNP had no effect on survival time $(\mathrm{P}>0.05)$. XRCCl-399 SNP was associated with the short-term therapeutic efficacy (the CR rate) and tumor metastasis/relapse in ESCC patients who received the docetaxel plus cisplatin (TP) regimen-based concurrent radiochemotherapy. By contrast, ERCC1-118 SNP was significantly associated with the short-term therapeutic efficacy (the CR rate) and survival time in ESCC patients who received TP regimen-based concurrent radiochemotherapy.

\section{Introduction}

In China, esophageal cancer is one of the most common gastrointestinal tract malignancies, and esophageal squamous cell carcinoma (ESCC) accounts for $>90 \%$ of all esophageal cancer cases $(1,2)$. As patients with esophageal cancer are often clinically diagnosed at advanced stages, surgery may not always be an option (3). At present, concurrent radiochemotherapy is the standard therapeutic regimen recommended internationally for patients who have inoperable esophageal cancer or choose not to undergo surgery (4). With the development of chemotherapy drugs and improvement in radiation therapy, radiochemotherapy continues to advance in the treatment of esophageal cancer (5-9). However, it has been found in clinical practice that concurrent radiochemotherapy 
causes serious toxicity and side effects in numerous patients. In addition, clinical practice has found that the efficacy of radiochemotherapy differs among patients with the same pathological types of esophageal cancer and at the same clinical stage. Therefore, achieving appropriate patient stratification, screening for biomarkers capable of predicting the efficacy of radiochemotherapy and prognosis, distinguishing between chemoradiotherapy-sensitive and chemoradiotherapy-insensitive esophageal cancer patients, avoiding under-treatment or overtreatment, and reducing adverse reactions are currently urgent issues that require resolution in clinical practice.

Platinum-based chemotherapy regimens are the most common chemotherapy regimens used during concurrent radiochemotherapy for the treatment of esophageal cancer (10-12). The mechanism by which platinum-based drugs kill tumor cells involves the formation of platinum-DNA complexes through binding of the drugs to cellular DNA (13). As a result, DNA interstrand or intrastrand cross-links are formed, and the structure and function of DNA are destroyed, eventually leading to cell death (13). Radiation therapy kills cells by directly or indirectly damaging cellular DNA and inducing DNA single-strand breaks (SSB) or double-strand breaks (DSB), thereby generating cytotoxicity (14,15). The repair of chemotherapy and radiotherapy-induced DNA damage is accomplished by the DNA repair system (16). DNA repair-associated genes play a crucial role in the process of repairing damaged DNA $(17,18)$. Inheritedor acquired defects in DNA repair genes may induce corresponding changes in the capacity of the cells to repair DNA damage and eventually affect the sensitivity of tumor cells to chemotherapy and radiation therapy (16).

A single-nucleotide polymorphism (SNP) refers to a genetic polymorphism generated by single-nucleotide substitution, insertion or deletion. SNPs are the most common polymorphisms that exist in the human genome. A single-base mutation in the gene sequence may alter the amino acids encoded by the gene or alter the splicing of transcribed mRNA, thus additionally affecting the function of the expressed protein. SNPs in DNA repair-associated genes may alter the amino acids encoded by the genes and subsequently change the activities of the corresponding DNA repair enzymes and affect DNA repair capability. Therefore, in the present study, the novel idea concerning whether the sensitivity of tumor cells to radiochemotherapy can be predicted through the examination of SNPs in DNA repair genes was tested.

In previous years, significant progress has been made in the study of DNA repair pathways. To date, four major DNA repair pathways have been identified: Base excision repair (BER); nucleotide excision repair (NER); double-strand break repair (DSBR); and mismatch repair (MMR) $(17,18)$. In total $>130$ genes are involved in DNA repair. Among the genes, 45 have been found to exhibit SNPs. Human X-ray repair cross-complementing 1 (XRCC1) is the first mammalian DNA repair gene isolated that affects cell sensitivity to ionizing radiation. XRCC1 participates in BER and single-strand break repair (SSBR) to eliminate the DNA damage induced by chemical mutagens and ionizing radiation $(19,20)$. The repair cross-complementation group 1 (ERCC1) is a key rate-limiting gene in the human NER pathway and plays a critical role in excision repair. In addition, ERCC1 is involved in the repair of
DNA double-strand cross-links and breaks (21-23). Currently, several studies have shown that SNPs at multiple loci of XRCC1 and ERCC1 genes are closely correlated with the susceptibility of various tumors and clinical efficacy (24-29). However, the majority of the studies were focused on the association between XRCC1 and ERCC1 SNPs and the sensitivity of various tumors to platinum-based chemotherapy (26-29). Studies focusing on radiation therapy are rare. Based on the aforementioned theoretical foundations, the present study mainly explored the association between XRCC1-399 and ERCC1-118 SNPs and the outcomes of concurrent radiochemotherapy in the treatment of ESCC, including the short-term efficacy, cancer metastasis, relapse and survival time. The purpose of the present study was to identify the genotype that was sensitive to radiochemotherapy. Thus, the individual differences in the sensitivity to radiochemotherapy can be predicted prior to treatment, and the clinical efficacy and prognosis of the patients can be successfully evaluated. Eventually, individualized therapeutic regimens may be developed to improve the cure rates and reduce the adverse side effects.

\section{Materials and methods}

Study population. The specimens examined in the present study were 50 ESCC patients first treated between April 2011 and March 2014 at the Department of Radiation Oncology, Changzhou Tumor Hospital Affiliated to Soochow University (Changzhou, Jiangsu, China). All patients enrolled in the present study met the following inclusion criteria: The age of the patients was not >70 years; the patients had no serious internal diseases; the Karnofsky scores were $\geq 70$; the patients had no lung, liver, bone or other metastases; and the patients were first-treated patients with diagnoses of stage II-III esophageal cancer that had been confirmed by pathological examination, esophageal imaging and computed tomography (CT) scan. The clinical stages of esophageal cancer were classified in accordance with the internationally accepted tumor node-metastasis staging system (7th edition) (30). The detailed clinical characteristics of the 50 patients are summarized in Table I.

Treatment methods. All patients were subjected to intensity-modulated radiation therapy (IMRT). Based on the location of the lesions, patients were immobilized using either a head-neck-and-shoulder mask system or a body mold. The patients underwent enhanced 64-slice spiral CT scans (5-mm slice thickness). Based on the lesion location indicated by CT, gastroscopy and double-oblique esophageal imaging, the target areas were outlined as follows: Gross tumor volume (GTV); clinical target volume (CTV); and planning target volume (PTV). GTV referred to the primary esophageal lesions, while clinical target volume of lymph nodes (GTVnd) referred to the enlarged metastatic lymph nodes. The CTV included GTV, GTVnd and the lymphatic drainage area. To obtain CTV, $3.0 \mathrm{~cm}$ was added to the top and bottom margins of GTV, while $0.8-1.0 \mathrm{~cm}$ were added to the left, right, front and rear margins. In addition, $1.0 \mathrm{~cm}$ was added around the margins of GTVnd, and the lymphatic drainage areas corresponding to a high rate of lymph-node metastasis were outlined. To obtain the PTV, the three dimensions of CTV were extended by $0.8 \mathrm{~cm}$. Subsequent to the extension proper 
modifications were made at the regions of anatomical barriers and the adjacent organs at risk (OARs). In addition, OARs including the heart, lungs and spinal cord were outlined. The treatment plans were evaluated and optimized based on the dose to the target regions, conformal degree, and dose volume histograms (DVH). IMRT was conducted using a linear accelerator at 6-MV X-ray energy. The prescribed dose to the PTV was $2.0 \mathrm{~Gy} /$ treatment. IMRT was performed five times per week for a total of 28-33 times. The absorbed dose DT was 56-66 Gy. The prescribed dose covered $95 \%$ of the PTV. The doses administered to the OARs were as follows: Lung, mean dose $<18 \mathrm{~Gy}, \mathrm{~V} 20<30 \%$ (both lungs); heart, mean dose $<30, \mathrm{~V} 30<46 \%$, V $40<40 \%$; and spinal cord, maximum dose $<45 \mathrm{~Gy}$. Two cycles of the TP regimen were adopted as the concurrent chemotherapy. The patients were administered docetaxel $\left(35 \mathrm{mg} / \mathrm{m}^{2}\right)$ and cisplatin (DDP, $\left.25-30 \mathrm{mg} / \mathrm{m}^{2}\right)$ on days 1,8 and 15 . The patients were then allowed to rest for one week prior to the start of the second cycle of chemotherapy.

DNA extraction and genotyping analysis. In total, $2 \mathrm{ml}$ of venous blood was extracted from each patient prior to therapy and mixed with anticoagulants. Subsequently, genomic DNA was isolated from whole blood. Genotyping of XRCC1-399 and ERCC1-118 was assessed using TaqMan probe-based quantitative polymerase chain reaction (qPCR). The XRCC1-399 and ERCC1-118 genotyping kits were designed and synthesized by Applied Biosystems (Thermo Fisher Scientific, Inc., Waltham, MA, USA). The PCR primers to amplify the DNA were as follows: ERCC1-118 forward, 5'-GTGCGAGGAGGCAGG AGGTGTGGG-3' and reverse, 5'-GAGCTCACCTGAGGA ACAGG-3'; XRCC1-399 forward, 5'-CCCCAAGTACAGCCA GGTCC-3' and reverse, 5'-CCGCTCCTCTCAGTAGTCTG-3'. GAPDH was used as the reference gene: Forward, 5'-GCACCG TCAAGGCTGAGAAC-3' and reverse, 5'-GGATCTCGCTCC TGGAAGATG-3', the primers were designed by GenePharma Co. Ltd. (Shanghai, China). qPCR was performed using a Stratagene Mx3000P (Agilent Technologies, Inc., Santa Clara CA, USA) as follows: The total volume of the reaction system was $20 \mu 1$, which contained 1X TaqMan PCR Master Mix (Applied Biosystems; Thermo Fisher Scientific, Inc.), $0.1 \mu 1$ template DNA, $300 \mathrm{nM}$ primers, $100 \mathrm{nM}$ wild-type probe and $100 \mathrm{nM}$

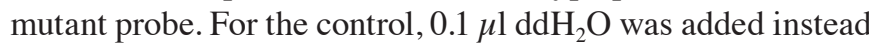
of the template DNA to exclude the systemic error. The amplification conditions were as follows: $50^{\circ} \mathrm{C}$ for $2 \mathrm{~min}, 95^{\circ} \mathrm{C}$ for $15 \mathrm{~min}, 1$ cycle and $95^{\circ} \mathrm{C}$ for $15 \mathrm{sec}, 60^{\circ} \mathrm{C}$ for $1 \mathrm{~min}, 45$ cycles. The genotypes were identified using MxPro-Mx3000P v4.00 analysis software (Agilent Technologies, Inc.). The data were analyzed using the $2^{-\Delta \Delta \mathrm{Ca}}$ method as described previously (31). The sequence chromatograms were analyzed by Chromas software (Technelysium Pty Ltd., South Brisbane, Australia) to search for SNPs at the target locus of each gene. All DNA samples were subjected to direct sequencing simultaneously. Subsequent to completion of the PCR reaction, the amplified fragments were identified by electrophoresis on $2 \%$ agarose gels and the PCR products were sequenced by the Shanghai Sangon Biotech Corp (Shanghai, China). The samples were determined from triplicate PCR and only the medical cases that produced consistent results in in the two types of assays were subjected to subsequent clinical significance analysis. The reproducibility of the two assays reaches $100 \%$.
Efficacy appraisal

Evaluation of the short-term therapeutic efficacy. At 1-3 months subsequent to completion of radiochemotherapy, barium X-rays of the esophagus were taken, and CT of the chest and upper abdomen was assessed to evaluate the short-term efficacy of radiochemotherapy. As several studies have repeatedly shown that achievement of complete remission (CR) following radiochemotherapy is an important factor affecting the long-term prognosis of patients with esophageal cancer $(32,33)$, the present study employed CR to evaluate the short-term efficacy. The criteria employed to evaluate short-term efficacy were from Version 1.1 of the Response Evaluation Criteria In Solid Tumors (RECIST) (34).

Evaluation of relapse and metastasis. The patients were checked regularly (every 2-3 months) during the first year subsequent to the treatment and once every 6 months following a year. Esophageal X-ray, systemic CT and enhanced CT (ECT) of the bones were conducted during the check-ups.

Evaluation of the long-term therapeutic efficacy. The 1-year, 2-year and 3-year survival rates, as well as the mean survival time of the patients, were determined.

Patient follow-up. The follow-up time referred to the time from the beginning of treatment until mortality or the last follow-up. The follow-up period ended on September 31, 2014. The follow-up rate was $100 \%$.

Statistical analysis. The different clinical characteristics of the 50 esophageal cancer patients, XRCC1-399 and ERCC1-118 SNPs, and the occurrence of CR, metastasis or relapse subsequent to radiochemotherapy were compared between the groups using $\chi^{2}$ test, Fisher's exact probability test or a logistic regression model. Survival analysis was assessed using the Kaplan-Meier method, and the log-rank test was conducted to test for significance. $\mathrm{P} \leq 0.05$ was considered to indicate a statistically significant difference. The association between various clinical features, XRCC1-399/ERCC1-118 SNP and survival time was calculated using univariate and multivariate Cox proportional hazards models. The efficacy is expressed as hazard ratios (HRs). The significance level was set to 5\%. Two-sided P-values were utilized. The $95 \%$ confidence interval (CI) was computed. Statistical analysis was assessed using STATA 13.0 software (StataCorp LP, College Station, TX, USA).

\section{Results}

Genotype distribution of XRCC1-399 and ERCC1-118. The SNPs at codon 399 of XRCC1 and codon 118 of ERCC1 were analyzed in the 50 ESCC patients. The results showed that $26 \%$ (13/50) of the patients carried wild-type XRCC1-399 (G/G genotype), $44 \%$ (22/50) carried the heterozygous mutation of XRCC1-399 (G/A genotype), and 30\% (15/50) carried the homozygous mutation of XRCC1-399 (A/A genotype). In addition, 48\% (24/50) of the patients carried wild-type ERCC1-118 (C/C genotype), 32\% (16/50) carried the heterozygous mutation of ERCC1-118 (C/T genotype), and 20\% (10/50) carried the homozygous mutation of ERCC1-118 (T/T genotype). The genotypes of XRCCl-399 and ERCC1-118 complied with 


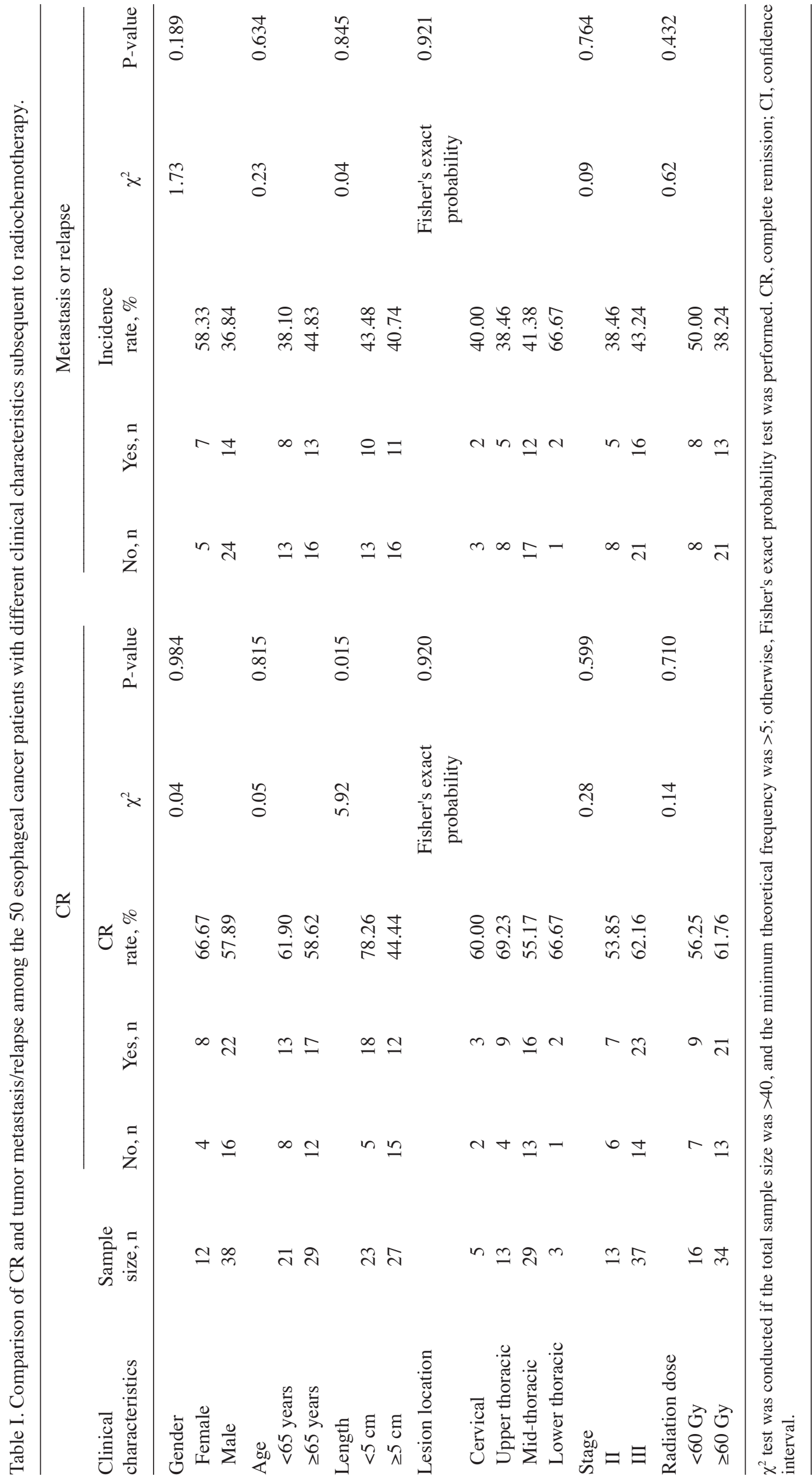


Table II. Association between different genotypes of X-ray repair cross-complementing 1-399 and short-term efficacy of radiochemotherapy (CR rate).

\begin{tabular}{lccccr}
\hline & & \multicolumn{2}{c}{ Short-term efficacy } & & \\
\cline { 3 - 4 } Genotype & Sample size, $\mathrm{n}$ & $\mathrm{CR}, \mathrm{n}(\%)$ & No CR, $\mathrm{n}(\%)$ & OR (95\% CI) & P-value \\
\hline $\mathrm{G} / \mathrm{G}$ & 13 & $5(38.46)$ & $8(61.54)$ & Ref. & \\
$\mathrm{G} / \mathrm{A}$ & 22 & $12(54.55)$ & $10(45.45)$ & $1.92(0.47-7.77)$ & 0.360 \\
$\mathrm{~A} / \mathrm{A}$ & 15 & $13(86.67)$ & $2(13.33)$ & $10.4(1.62-66.90)$ & 0.014 \\
G/A+A/A & 37 & $25(67.57)$ & $12(32.43)$ & $3.33(0.90-12.38)$ & 0.072 \\
\hline
\end{tabular}

Comparison between the groups was assessed using logistic regression analysis. CR, complete remission; CI, confidence interval; Ref., reference.

Table III. Association between different genotypes of excision repair cross-complementing group 1-118 and the short-term efficacy of radiochemotherapy (CR rate).

\begin{tabular}{|c|c|c|c|c|c|}
\hline \multirow[b]{2}{*}{ Genotype } & \multirow[b]{2}{*}{ Sample size, $\mathrm{n}$} & \multicolumn{2}{|c|}{ Short-term efficacy } & \multirow[b]{2}{*}{ OR $(95 \% \mathrm{CI})$} & \multirow[b]{2}{*}{ P-value } \\
\hline & & $\mathrm{CR}, \mathrm{n}(\%)$ & No CR, n (\%) & & \\
\hline $\mathrm{C} / \mathrm{C}$ & 24 & $17(56.67)$ & $7(35.00)$ & Ref. & \\
\hline $\mathrm{C} / \mathrm{T}$ & 16 & $10(33.33)$ & $6(30.00)$ & $0.69(0.18-2.62)$ & 0.582 \\
\hline $\mathrm{T} / \mathrm{T}$ & 10 & $3(10.00)$ & $7(35.00)$ & $0.18(0.04-0.89)$ & 0.035 \\
\hline $\mathrm{C} / \mathrm{C}$ & 24 & $17(56.67)$ & $7(35.00)$ & Ref. & \\
\hline $\mathrm{C} / \mathrm{T}+\mathrm{T} / \mathrm{T}$ & 26 & $13(43.33)$ & $13(65.00)$ & $0.41(0.13-1.32)$ & 0.137 \\
\hline $\mathrm{T} / \mathrm{T}$ & 10 & $3(10.00)$ & $7(35.00)$ & Ref. & \\
\hline $\mathrm{C} / \mathrm{C}+\mathrm{C} / \mathrm{T}$ & 40 & $27(90.00)$ & $13(65.00)$ & $4.85(1.08-21.84)$ & 0.040 \\
\hline
\end{tabular}

Comparison between the groups was conducted using logistic regression analysis. CR, complete remission; CI, confidence interval; Ref., reference; OR, odds ratio.

Hardy-Weinberg equilibrium (the genotypes of XRCCl-399, $\mathrm{P}=0.704$; the genotypes of ERCC1-118, $\mathrm{P}=0.097$ ).

Association between different XRCC1-399 and ERCC1-118 genotypes and the short-term efficacy of radiochemotherapy (CR rate). The distribution of the three genotypes of XRCC1-399 (G/G, G/A and A/A) in the 50 ESCC patients and short-term efficacy of radiochemotherapy (which was represented by the CR rate) were compared, and the results are shown in Table II. The CR rate showed an upward trend in the mutated XRCC1-399 group (G/A+A/A genotypes) compared with the non-mutated XRCC1-399 group (the G/G genotype). However, the difference was not statistically significant $(\mathrm{P}=0.072)$. Additional analysis revealed that there was a statistically significant difference in the CR rate between the group of patients carrying the homozygous mutation in XRCC1-399 (the A/A genotype) and patients carrying the non-mutated XRCC1-399 ( $\mathrm{P}=0.014)$. These results indicated that the patients with the XRCC1-399 A/A genotype were more sensitive to concurrent radiochemotherapy. The distribution of the three genotypes of ERCC1-118 (C/C, C/T and $\mathrm{T} / \mathrm{T}$ ) in the 50 ESCC patients and short-term efficacy of the radiochemotherapy (the CR rate) were compared, and the results are shown in Table III. Compared with patients lacking the $\mathrm{C}$ allele (the $\mathrm{T} / \mathrm{T}$ genotype), patients carrying one or two $\mathrm{C}$ alleles $(\mathrm{C} / \mathrm{C}$ or $\mathrm{C} / \mathrm{T}$ genotypes) showed increased sensitivity to concurrent radiochemotherapy. The differences in the $\mathrm{CR}$ rates were statistically significant $(\mathrm{P}=0.040)$.

Association between different XRCC1-399 and ERCC1-118 genotypes and ESCC metastasis/relapse. The distribution of the three genotypes of XRCC1-399 (G/G, G/A and A/A) among the 50 ESCC patients and occurrence of metastasis or relapse in the patients during the follow-up period was examined, and the results are summarized in Table IV. Compared with the non-mutated XRCC1-399 group (G/G genotype), the difference in the distribution of the mutated XRCC1-399 group (G/A+A/A genotype) between the metastasis/relapse-positive and metastasis/relapse-negative groups was not statistically significant $(\mathrm{P}=0.104)$. However, additional analysis revealed that the risk of metastasis or relapse was markedly reduced in patients carrying the homozygous mutation of XRCC1-399 (A/A genotype). The difference was statistically significant $(\mathrm{P}=0.031)$. The distribution of the three genotypes of ERCC1-118 (C/C, C/T and T/T) and occurrence of metastasis or relapse in the 50 ESCC patients were compared, and the results are summarized in Table V. No statistically significant differences were detected 
Table IV. Association between different genotypes of X-ray repair cross-complementing 1-399 and the occurrence of metastasis or relapse.

\begin{tabular}{|c|c|c|c|c|c|}
\hline \multirow[b]{2}{*}{ Genotype } & \multirow[b]{2}{*}{ Sample size, $\mathrm{n}$} & \multicolumn{2}{|c|}{ Metastasis or relapse } & \multirow[b]{2}{*}{ OR $(95 \% \mathrm{CI})$} & \multirow[b]{2}{*}{ P-value } \\
\hline & & Positive, n (\%) & Negative, n (\%) & & \\
\hline $\mathrm{G} / \mathrm{G}$ & 13 & $8(61.54)$ & $5(38.46)$ & Ref. & \\
\hline $\mathrm{G} / \mathrm{A}$ & 22 & $10(45.45)$ & $12(54.55)$ & $0.51(0.13-2.11)$ & 0.360 \\
\hline $\mathrm{A} / \mathrm{A}$ & 15 & $3(20.00)$ & $12(80.00)$ & $0.16(0.03-0.85)$ & 0.031 \\
\hline $\mathrm{G} / \mathrm{A}+\mathrm{A} / \mathrm{A}$ & 37 & $13(35.14)$ & $24(64.86)$ & $0.34(0.09-1.25)$ & 0.104 \\
\hline
\end{tabular}

Comparison between the groups was conducted using logistic regression analysis. CI, confidence interval; Ref., reference; OR, odds ratio.

Table V. Association between different genotypes of excision repair cross-complementing group 1-118 and the occurrence of metastasis or relapse.

\begin{tabular}{|c|c|c|c|c|c|}
\hline \multirow[b]{2}{*}{ Genotype } & \multirow[b]{2}{*}{ Sample size } & \multicolumn{2}{|c|}{ Metastasis or relapse } & \multirow[b]{2}{*}{ OR (95\% CI) } & \multirow[b]{2}{*}{$\mathrm{P}$-value } \\
\hline & & Positive (\%) & Negative (\%) & & \\
\hline $\mathrm{C} / \mathrm{C}$ & 24 & $9(42.86)$ & $15(51.72)$ & Ref. & \\
\hline $\mathrm{C} / \mathrm{T}$ & 16 & $8(38.10)$ & $8(27.59)$ & $1.67(0.46-6.01)$ & 0.435 \\
\hline $\mathrm{T} / \mathrm{T}$ & 10 & $4(19.05)$ & $6(20.69)$ & $1.11(0.25-5.04)$ & 0.891 \\
\hline $\mathrm{C} / \mathrm{C}$ & 24 & $9(42.86)$ & $15(51.72)$ & Ref. & \\
\hline $\mathrm{C} / \mathrm{T}+\mathrm{T} / \mathrm{T}$ & 26 & $12(57.14)$ & $14(48.28)$ & $1.43(0.46-4.42)$ & 0.536 \\
\hline $\mathrm{T} / \mathrm{T}$ & 10 & $4(19.05)$ & $6(20.69)$ & Ref. & \\
\hline $\mathrm{C} / \mathrm{C}+\mathrm{C} / \mathrm{T}$ & 40 & $17(80.95)$ & $23(79.31)$ & $1.11(0.27-4.55)$ & 0.886 \\
\hline
\end{tabular}

Comparison between the groups was conducted using logistic regression analysis. CI, confidence interval.

regarding the risk of metastasis or relapse between patients carrying one or two $\mathrm{C}$ alleles $(\mathrm{C} / \mathrm{C}$ or $\mathrm{C} / \mathrm{T}$ genotypes) and patients lacking the $\mathrm{C}$ allele (the $\mathrm{T} / \mathrm{T}$ genotype; $\mathrm{P}>0.05$ ).

Association between different genotypes of XRCC1-399 or ERCC1-118 and the survival time of ESCC patients treated with radiochemotherapy. The association between XRCC1-399 SNP genotypes and survival time was examined in the 50 ESCC patients, and the survival curves are shown in Figs. 1 and 2. Compared with the non-mutated group (G/G genotype), the survival time of patients carrying the heterozygous XRCC1-399 mutation (G/A genotype) and the homozygous mutation of XRCC1-399 (A/A genotype) was extended. However, the difference was not statistically significant $(\mathrm{P}=0.283)$. The mutated XRCC1-399 group (G/A+A/A genotypes) included patients with either G/A or A/A genotype. Compared with the non-mutated group (G/G genotype), the median survival time was prolonged. However, the difference was not statistically significant $(\mathrm{P}=0.208)$. The association between different genotypes of ERCC1-118 and survival time was examined in the 50 ESCC patients, and the survival curves are shown in Figs. 3 and 4. Compared with patients lacking the $\mathrm{C}$ allele (T/T genotype), the mean survival time was prolonged in patients carrying one or two $\mathrm{C}$ alleles (C/C or $\mathrm{C} / \mathrm{T}$ genotype). The difference was statistically significant $(\mathrm{P}<0.001)$.
Association between various clinical features and survival time in ESCC patients treated with concurrent radiochemotherapy. A univariate Cox proportional hazards model was utilized to analyze the association between the survival time and several factors, including gender, age, length of the tumor, tumor location, clinical stage, radiation dose, and XRCC1-399 and ERCC1-118 gene polymorphism in ESCC patients treated with radiochemotherapy (Table VI). A multivariate Cox proportional hazards model was employed to analyze the survival time of the patients and hazard ratios (Table VII). Subsequent to combining with univariate analysis and adjusting for confounders such as gender, tumor length and radiation dose, multivariate Cox regression analysis showed there was no statistically significant association between XRCC1-399 gene polymorphisms and survival time $(\mathrm{P}>0.05)$. By contrast, ERCC1-118 gene polymorphisms were closely associated to survival time. Compared with patients lacking the $\mathrm{C}$ allele (T/T genotype), patients carrying one or two $\mathrm{C}$ alleles, consisting of the $\mathrm{C} / \mathrm{C}(\mathrm{HR}=12.96,95 \% \mathrm{CI}(3.08-54.61)$, $\mathrm{P}<0.001)$ or $\mathrm{C} / \mathrm{T}(\mathrm{HR}=11.71,95 \% \mathrm{CI}(3.06-44.83), \mathrm{P}<0.001)$ genotype, experienced significantly prolonged survival.

\section{Discussion}

At present, the internationally recommended standard therapeutic regimen for esophageal cancer patients who cannot 
Table VI. Analysis of various clinical features, XRCC1-399 and ERCC1-118 SNPs and survival time using univariate Cox proportional hazards model.

\begin{tabular}{lccccr}
\hline Factor & Coefficient & Standard error & Statistic value & HR (95\% CI) & P-value \\
\hline Gender & -0.47 & 0.47 & 1.00 & $0.62(0.25-1.58)$ & 0.318 \\
Age & 0.09 & 0.46 & 0.04 & $1.09(0.45-2.68)$ & 0.846 \\
Tumor length & 0.25 & 0.48 & 0.27 & $1.29(0.50-3.28)$ & 0.600 \\
Tumor location & & & & \\
Upper thoracic vs. cervical & -0.24 & 0.87 & 0.08 & $0.79(0.14-4.31)$ & 0.784 \\
Mid thoracic vs. cervical & 0.21 & 0.76 & 0.07 & $1.23(0.27-5.49)$ & 0.788 \\
Lower thoracic vs. cervical & 0.47 & 1.00 & 0.22 & $1.60(0.22-11.40)$ & 0.640 \\
Test for trend in tumor location & 0.23 & 0.30 & 0.58 & $1.26(0.70-2.27)$ & 0.448 \\
Clinical stage & -0.06 & 0.49 & 0.01 & $0.94(0.36-2.45)$ & 0.904 \\
Radiation dose & -0.87 & 0.46 & 3.61 & $0.42(0.17-1.03)$ & 0.058 \\
XRCC1-399 & & & & & \\
G/A vs. G/G & -0.35 & 0.51 & 0.48 & $0.70(0.26-1.90)$ & 0.487 \\
A/A vs. G/G & -0.97 & 0.63 & 2.36 & $0.38(0.11-1.31)$ & 0.125 \\
G/A+A/A vs. G/G & -0.59 & 0.48 & 1.51 & $0.56(0.22-1.42)$ & 0.219 \\
A/A vs. G/A vs. G/G & -0.47 & 0.30 & 2.42 & $0.62(0.34-1.13)$ & 0.120 \\
ERCC1-118 & & & & & 0.490 \\
C/T vs. C/C & 0.41 & 0.59 & 0.48 & $1.50(0.47-4.74)$ & 0.490 \\
T/T vs. C/C & 2.01 & 0.54 & 14.04 & $7.46(2.61-21.35)$ & $<0.001$ \\
C/T+T/T vs. C/C & 1.06 & 0.47 & 5.00 & $2.88(1.14-7.29)$ & 0.025 \\
TT vs. C/T+C/C & 1.86 & 0.47 & 5.29 & $6.40(2.52-16.22)$ & $<0.001$ \\
TT vs. C/T vs. C/C & 1.01 & 0.29 & 12.03 & $2.75(1.55-4.88)$ & $<0.001$ \\
\end{tabular}

XRCC1, X-ray repair cross-complementing 1; ERCC1, excision repair cross-complementing group 1; CI, confidence interval.

Table VII. Analysis of patient survival time and hazard ratios using the multivariate Cox proportional hazards model.

\begin{tabular}{lcccc}
\hline Factor & Coefficient & Standard error & Statistic value & HR (95\% CI $)$ \\
\hline XRCC1-399 & & & & \\
G/A vs. G/G & -0.32 & 0.55 & 0.35 & $0.72(0.25-2.12)$ \\
A/A vs. G/G & -0.32 & 0.73 & 0.19 & $0.73(0.17-3.02)$ \\
G/A+A/A vs. G/G & -0.32 & 0.53 & 0.37 & $0.73(0.26-2.03)$ \\
A/A vs. G/A vs. G/G & -0.18 & 0.37 & 0.25 & $0.83(0.41-1.70)$ \\
ERCC1-118 & & & & 0.659 \\
C/T vs. C/C & 0.24 & 0.60 & 0.16 & $1.27(0.39-4.12)$ \\
T/T vs. C/C & 2.56 & 0.73 & 12.19 & $12.96(3.08-54.61)$ \\
C/T+T/T vs. C/C & 0.86 & 0.49 & 3.10 & $2.37(0.91-6.18)$ \\
TT vs. C/T+C/C & 2.46 & 0.69 & 12.90 & $11.71(3.06-44.83)$ \\
TT vs. C/T vs. C/C & 1.12 & 0.37 & 9.32 & $3.08(1.50-6.34)$ \\
\hline
\end{tabular}

The multivariate Cox proportional hazards model was adjusted for multiple confounders such as gender, tumor length and radiation dose. XRCC1, X-ray repair cross-complementing; CI, confidence interval.

or choose not to have surgery is concurrent radiochemotherapy (4). Effective prediction of the individual differences in the sensitivity to radiochemotherapy prior to the treatment is of significant clinical value as it allows for the development of individualized therapeutic regimens based on different clinical features of the patients. Individualized therapy may enhance cure rates and reduce adverse effects (35).

It has been repeatedly proven that the achievement of CR following radiochemotherapy is one of the important factors for the long-term prognosis of patients with esophageal 


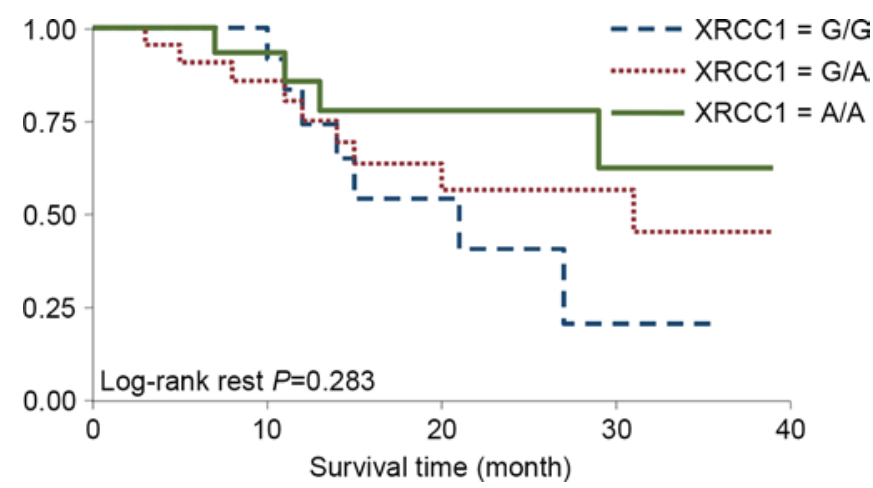

Figure 1. Comparison of the survival time of the XRCC1-399 genotypes (G/G, G/A or A/A). XRCC1, X-ray repair cross-complementing 1. Compared with the non-mutated group (G/G genotype), the survival time of patients carrying the heterozygous XRCC1-399 mutation (G/A genotype) and the homozygous mutation of XRCC1-399 (A/A genotype) was extended. However, the difference was not statistically significant $(\mathrm{P}=0.283)$.

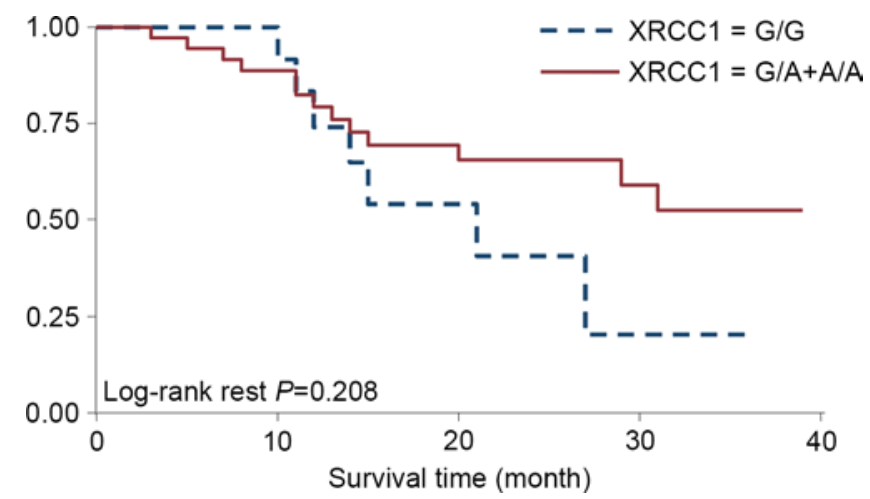

Figure 2. Comparison of the survival time of XRCC1-399 genotypes (G/G or $\mathrm{G} / \mathrm{A}+\mathrm{A} / \mathrm{A})$. XRCC1, X-ray repair cross-complementing 1 . The mutated XRCC1-399 group (G/A+A/A genotypes) included patients with either G/A or A/A genotype. Compared with the non-mutated group (G/G genotype), the median survival time was prolonged. However, the difference was not statistically significant $(\mathrm{P}=0.208)$.

cancer $(32,33)$. Yoon and Forastiere (36) reported that the overall survival (OS) rate of esophageal cancer is strongly correlated with whether or not CR is achieved subsequent to radiochemotherapy. Therefore, the current study chose the CR rate of esophageal cancer following radiochemotherapy as an endpoint in the examination of the short-term efficacy of the radiochemotherapy.

The XRCC1 gene is involved in several DNA repair processes, including BER and SSBR (20). Cornetta et al (37) irradiated the peripheral blood cells collected from 50 healthy individuals with X-rays. Subsequent to 2 Gy of irradiation, the blood cells were analyzed immediately via comet assay, and XRCC1 genotypes were examined simultaneously. The results showed that the comet tail was significantly longer in cells carrying the homozygous glutamine (Gln) allele (XRCC1 codon $399 \mathrm{Gln} / \mathrm{Gln}$ ) than heterozygous arginine (Arg)/Gln and wild-type Arg/Arg cells. Similar results were obtained following 30 and $60 \mathrm{~min}$. These results demonstrated that cells with the Gln/Gln genotype exhibit increased radiosensitivity compared with cells with other genotypes. Therefore, the study conducted by Cornetta et al indicates that the sensitivity to radiotherapy is associated

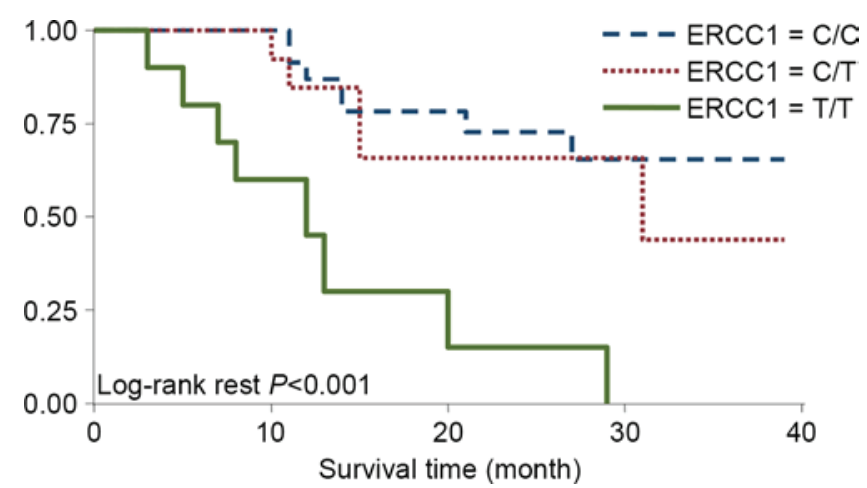

Figure 3. Comparison of the survival time of ERCC1-118 genotypes (C/C, C/T or T/T). ERCC1, excision repair cross-complementing group 1. Compared with patients lacking the $\mathrm{C}$ allele (T/T genotype), the mean survival time was prolonged in patients carrying one or two $\mathrm{C}$ alleles (C/C or $\mathrm{C} / \mathrm{T}$ genotype). The difference was statistically significant $(\mathrm{P}<0.001)$.

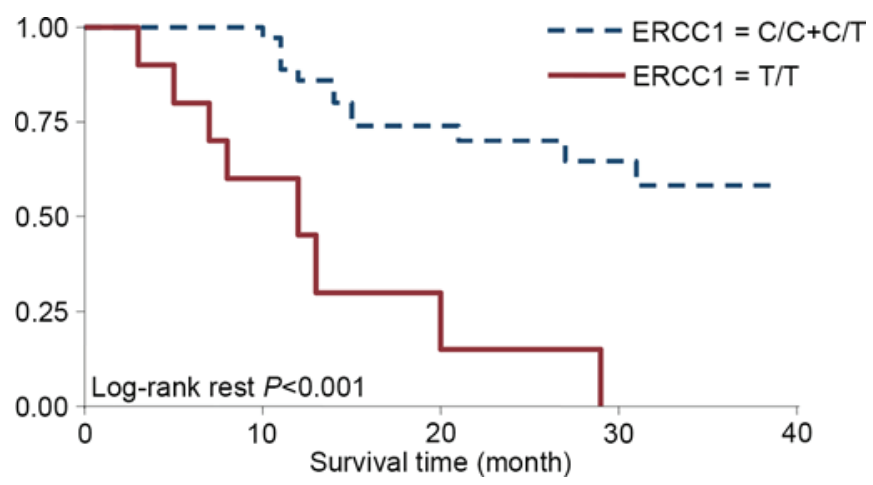

Figure 4. Comparison of the survival time of ERCC1-118 genotypes (T/T or $\mathrm{C} / \mathrm{C}+\mathrm{C} / \mathrm{T})$. ERCC1, excision repair cross-complementing group 1. Compared with patients lacking the $\mathrm{C}$ allele (T/T genotype), the mean survival time was prolonged in the total of patients carrying one or two $\mathrm{C}$ alleles $(\mathrm{C} / \mathrm{C}+\mathrm{C} / \mathrm{T}$ genotype). The difference was statistically significant $(\mathrm{P}<0.001)$.

with XRCC1 gene polymorphism. Wu et al (38) examined XRCC1 Arg399Gln SNPs in 210 esophageal cancer patients treated with preoperative adjuvant radiochemotherapy. This study found that the risk of mortality subsequent to radiochemotherapy was significantly increased in patients with mutant genotypes of XRCC1 Arg399Gln (G/A+A/A) compared with patients with the non-mutant genotype $(\mathrm{G} / \mathrm{G})$. The median survival times of patients with the G/A and A/A genotypes were 22.9 months and 13.7 months, respectively, while the median survival time of patients with the $\mathrm{G} / \mathrm{G}$ genotype was extended to 57.4 months. The differences were statistically significant $(\mathrm{P}<0.05)$. The present study also showed that the rate of histopathological CR following radiochemotherapy was markedly reduced in patients with the $\mathrm{G} / \mathrm{A}$ and $\mathrm{A} / \mathrm{A}$ genotypes compared with patients with the $\mathrm{G} / \mathrm{G}$ genotype. Yoon et al (39) conducted a retrospective cohort study to analyze the association between mutations in certain DNA repair pathway genes and the rate of histopathological remission in patients with esophageal adenocarcinoma subsequent to radiochemotherapy. This study showed that, among the 60 esophageal adenocarcinoma specimens examined, only 6\% (2/31) of the specimens with XRCC1 Arg399Gln gene mutations (Arg/Arg or Arg/Gln genotype) exhibited histopathological CR. By contrast, histopathological CR 
was achieved in $28 \%(8 / 29)$ of the specimens without gene mutation (Gln/Gln genotype). These results suggested that the Arg/Arg or Arg/Gln genotype may be negatively associated with the efficacy of radiochemotherapy. However, the association was not statistically significant $(\mathrm{P}=0.062)$.

The present study found that the mutant allele of XRCC1 Arg399GIn was present in $52 \%$ of ESCC patients. The short-term efficacy of radiochemotherapy (CR rate) was significantly higher in patients carrying the homozygous XRCC1 mutation (the A/A genotype) than in patients in the non-mutated group $(\mathrm{G} / \mathrm{G}$ genotype) $(\mathrm{P}=0.014)$. The risk of relapse or metastasis was reduced in patients carrying the homozygous XRCC1 mutation, and the difference was also statistically significant $(\mathrm{P}=0.031)$. Compared with the non-mutated group (G/G genotype), patients in the homozygous mutation group (A/A genotype) experienced a prolonged survival. However, the difference was not statistically significant $(\mathrm{P}>0.05)$. There are evident inconsistencies between the present findings and the results obtained by $\mathrm{Wu}$ et al (38) and Yoon et al (39). The study conducted by $\mathrm{Wu}$ et al was a retrospective study. The cases examined in the study of Wu et al spanned a long period of time (1985-2003). Certain patients received induction chemotherapy prior to concurrent radiochemotherapy. The cases studied included squamous cell carcinoma and adenocarcinoma. In addition, surgery was included when calculating the median survival time. All cases collected in the study by Yoon et al were adenocarcinomas. The population examined was predominantly Caucasian individuals. Patients with Mla stage cancer were included in the study. Cancers located at the gastroesophageal junction were also included in the study. In terms of chemotherapeutic drug selection, one group of patients received irinotecan plus cisplatin, while the other group received paclitaxel plus cisplatin. The present study has the innovativeness compared with the aforementioned studies by Wu et al and Yoon et al in the following aspects. Firstly, it contains recent data, with the cases collected spanning between April 2011 and March 2014. Secondly, all cases studied were squamous cell carcinoma; the lesions were located within the cervical and thoracic parts of the esophagus; and all of the cancers were in stage II and III. Thirdly, the individuals studied were exclusively Han Chinese who were born in areas south of the Yangtze River, China. Fourthly, all patients were uniformly treated with IMRT in combination with the docetaxel/cisplatin chemotherapeutic regimen. Finally, the specimens examined in the current study were peripheral blood readily collected from the patients. Genotyping was conducted using the TaqMan probe-based qPCR assay. Compared with conventional reverse transcription PCR-DNA restriction fragment length polymorphism (RT-RFLP) analysis, the TaqMan probe-based qPCR assay is more objective, efficient and accurate, and less time consuming.

The ERCC1 binds to its ligand xeroderma pigmentosum complementation group $\mathrm{F}$ (XPF), forming the ERCC1/XPF heterodimer. The ERCC1/XPF heterodimer has 5' DNA endonuclease activity, which excises the damaged DNA strand 15-24 nucleotides away from the lesion. In addition, the ERCC1/XPF heterodimer recognizes DNA damage and removes the 5' end. Therefore, ERCC1/XPF heterodimer plays a rate-limiting or regulatory role in nucleotide excision repair
(NER) (40,41). Risom et al (42) irradiated mouse lung cells with X-rays and examined the expression levels of ERCC1. It was found that the ERCC1 level was increased 2.5 -fold in mouse lung cells subsequent to $6 \mathrm{~h}$ of irradiation compared with the ERCC1 level prior to irradiation, indicating that the ERCC1 gene is an important gene required for the repair of DNA damage following X-ray irradiation. Several studies have shown that ERCC1-118 gene polymorphism affects cell sensitivity to platinum-based chemotherapy (43-45). A C-to-T mutation at codon 118 of ERCC1 results in decreased sensitivity to platinum-class drugs in patients. Compared with patients with the $\mathrm{T} / \mathrm{T}$ genotype, patients with a $\mathrm{C} / \mathrm{C}$ or $\mathrm{C} / \mathrm{T}$ genotype are more sensitive to platinum-class drugs and have a prolonged median survival time. However, studies focusing on the effect of ERCC1 on the efficacy of radiation therapy are rather rare. Warnecke-Eberz et al (46) investigated the feasibility of using ERCC1 gene polymorphisms to predict the efficacy of preoperative neoadjuvant chemotherapy for the treatment of esophageal cancer. The study found that the ERCC1 C118T genotype is associated with the efficacy of radiochemotherapy in patients with esophageal cancer. Compared with patients with the T/T genotype, patients with the $\mathrm{C} / \mathrm{T}$ genotype exhibited significantly increased histopathological responses (CR) subsequent to radiochemotherapy, most likely as the T/T genotype leads to reduced expression of ERCC1 mRNA and protein. The present study also verified the aforementioned finding. It found that, compared with patients lacking the ERCC1-118 C allele (T/T genotype), patients carrying one or two $\mathrm{C}$ alleles, consisting of the $\mathrm{C} / \mathrm{C}$ (HR, 12.96; 95\% CI, 3.08-54.61; $\mathrm{P}<0.001)$ or $\mathrm{C} / \mathrm{T}$ (HR, 11.71; 95\% CI, 3.06-44.83; $\mathrm{P}<0.001)$ genotype, were more sensitive to synchronous radiochemotherapy $(\mathrm{P}=0.040)$ and showed a significantly prolonged mean survival time.

The present study focused on ESCC, as ESCC accounts for $>90 \%$ of all esophageal cancer cases in China $(1,2)$. Compared with adenocarcinoma, ESCC exhibits notable differences in disease epidemiology and potential disease biology (47). Considerable efforts have been made towards developing biomarkers capable of predicting the prognosis of ESCC (48-50). However, the induction of DNA damage by radiation therapy or chemotherapy involves multiple genes and multiple steps (13-15). Therefore, the present study speculates that it is difficult to use one or two SNPs or biomarkers to predict therapeutic efficacy. Instead, a combination of multiple markers may be required in clinical practice.

In summary, the present study showed that XRCC1-399 SNP was associated with short-term therapeutic efficacy (CR rate) and tumor metastasis/relapse in ESCC patients who received TP regimen-based concurrent radiochemotherapy. By contrast, ERCC1-118 SNP was associated with short-term therapeutic efficacy (CR rate) and survival time in ESCC patients who received TP regimen-based concurrent radiochemotherapy. However, the sample size in the present study was rather small. To additionally define the association between $\mathrm{XRCCl}$ /ERCC1 SNPs and the efficacy of radiochemotherapy, tumor metastasis/relapse and survival time in ESCC patients, and to eventually develop individualized therapeutic regimens based on factors including the patients' ethnicity, genetic background and clinical characteristics, a multicenter prospective study with a large sample size is required. 
XRCCl-399 SNP was associated with the short-term therapeutic efficacy (the CR rate) and tumor metastasis/relapse in ESCC patients who received the TP (docetaxel plus cisplatin) regimen-based concurrent radiochemotherapy. By contrast, ERCC1-118 SNP was significantly associated with the short-term therapeutic efficacy (the CR rate) and survival time in ESCC patients who received the TP regimen-based concurrent radiochemotherapy.

\section{Acknowledgements}

This study was supported by the National Natural Science Foundation of China (grant no., 81402518), Jiangsu Provincial Special Program of Medical Science (grant no., BE2015631), Changzhou Sci\&Tech Program (grant no., CJ20112019), Natural Science Foundation of Jiangsu (grant no., BK20151174), Scientific Research of Changzhou (grant nos., CJ20159038 and QN201503). The authors thank Dr Xiuyuan Ou for comments on this manuscript.

\section{References}

1. Torre LA, Bray F, Siegel RL, Ferlay J, Lortet-Tieulent J and Jemal A: Global cancer statistics, 2012. CA Cancer J Clin 65: 87-108, 2015.

2. Hongo M, Nagasaki Y and Shoji T: Epidemiology of esophageal cancer: Orient to Occident. Effects of chronology, geography and ethnicity. J Gastroenterol Hepatol 24: 729-735, 2009.

3. Kanai M, Matsumoto S, Nishimura T, Shimada Y, Watanabe G, Kitano T, Misawa A, Ishiguro H, Yoshikawa K, Yanagihara K, et al: Retrospective analysis of 27 consecutive patients treated with docetaxel/nedaplatin combination therapy as a second-line regimen for advanced esophageal cancer. Int J Clin Oncol 12: 224-227, 2007.

4. Cooper JS, Guo MD, Herskovic A, Macdonald JS Martenson JA Jr, Al-Sarraf M, Byhardt R, Russell AH, Beitler JJ, Spencer S, et al: Chemoradiotherapy of locally advanced escophageal cancer: Long-term follow-up of a prospective randomized trial (RTOG85-01). Radiation therapy oncology group. JAMA 281: 1623-1627, 1999.

5. van Hagen P, Hulshof MC, van Lanschot JJ, Steyerberg EW, van Berge Henegouwen MI, Wijnhoven BP, Richel DJ, Nieuwenhuijzen GA, Hospers GA, Bonenkamp JJ, et al: Preoperative chemoradiotherapy for esophageal or junctional cancer. N Engl J Med 366: 2074-2084, 2012.

6. Lee MS, Mamon HJ, Hong TS, Choi NC, Fidias PM, Kwak EL, Meyerhardt JA, Ryan DP, Bueno R, Donahue DM, et al: Preoperative cetuximab, irinotecan, cisplatin, and radiation therapy for patients with locally advanced esophageal cancer. Oncologist 18: 281-287, 2013

7. Nutting CM, Bedford JL, Cosgrove VP, Tait DM, Dearnaley DP and Webb S: A comparison of conformal and intensity-modulated techniques for oesophageal radiotherapy. Radiother Oncol 61: $157-163,2001$

8. Lin SH, Wang L, Myles B, Thall PF, Hofstetter WL, Swisher SG, Ajani JA, Cox JD, Komaki R and Liao Z: Propensity score-based comparison of long-term outcomes with 3-dimensional conformal radiotherapy vs intensity-modulated radiotherapy for esophageal cancer. Int J Radiat Oncol Biol Phys 84: 1078-1085, 2012.

9. Yu CX and Tang G: Intensity-modulated arc therapy: Principles, technologies and clinical implementation. Phys Med Biol 56: R31-R54, 2011

10. Hayashi K, Ando N, Watanabe H, Ide H, Nagai K, Aoyama N, Takiyama W, Ishida $\mathrm{K}$, Isono $\mathrm{K}$, Makuuchi $\mathrm{H}$, et al: Phase II evaluation of protracted infusion of cisplatin and 5-fluorouracil in advanced squamous cell carcinoma of the esophagus: A Japan esophageal oncology group (JEOG) Trial (JCOG9407). Jpn J Clin Oncol 31: 419-423, 2001.

11. Bleiberg H, Conroy T, Paillot B, Lacave AJ, Blijham G, Jacob JH, Bedenne L, Namer M, De Besi P, Gay F, et al: Randomised phase II study of cisplatin and 5-fluorouracil (5-FU) versus cisplatin alone in advanced squamous cell oesophageal cancer. Eur J Cancer 33: 1216-1220, 1997.
12. Huang J, Zhou Y, Zhang H, Qu T, Mao Y, Zhu H, Quan L, Xing P, Wang J, He J, et al: A phase II study of biweekly paclitaxel and cisplatin chemotherapy for recurrent or metastatic esophageal squamous cell carcinoma: ERCC1 expression predicts response to chemotherapy. Med Oncol 30: 343, 2013.

13. Rosell R, Lord RV, Taron M and Reguart N: DNA repair and cisplatin resistance in non-small-cell lung cancer. Lung Cancer 38: 217-227, 2002.

14. Powell S and McMillan TJ: DNA damage and repair following treatment with ionizing radiation. Radiother Oncol 19: 95-108, 1990.

15. Malyapa RS, Bi C, Ahem EW and Roti Roti JL: Detection of DNA damage by the alkaline comet assay after exposure to low-dose gamma radiation. Radiat Res 149: 396-400, 1998.

16. Kim MK, Cho KJ, Kwon GY, Park SI, Kim YH, Kim JH, Song HY, Shin JH, Jung HY, Lee GH, et al: Patients with ERCC1-negative locally advanced esophageal cancers may benefit from preoperative chemoradiotherapy. Clin Cancer Res 14: 4225-4231, 2008

17. Lindahl T and Wood RD: Quality control by DNA repair. Science 286: 1897-1905, 1999.

18. Wood RD, Mitchell M, Sgouros J and Lindahl T: Human DNA repair genes. Science 291: 1284-1289, 2001.

19. Thompson LH, Brookman KW, Jones NJ, Allen SA and Carrano AV: Molecular cloning of the human XRCC1 gene, which contacts defective DNA strand-break repair and sister chromatid exchange. Mol Cell Biul 10: 6160-6171, 1990.

20. Thompson LH and West MG: XRCC1 keeps DNA from getting stranded. Mutat Res 459: 1-18, 2000.

21. van Duin M, de Wit J, Odijk H, Westerveld A, Yasui A, Koken MH, Hoeijmakers JH and Bootsma D: Molecular characterization of the human excision repair gene ERCC-1: cDNA cloning and amino acid homology with the yeast DNA repair gene RADIO. Cell 44: 913-923, 1986.

22. Su Y, Orelli B, Madireddy A, Niedernhofer LJ and Schärer OD: Multiple DNA binding domains mediate the function of the ERCC1-XPF protein in nucleotide excision repair. J Biol Chem 287: 21846-21855, 2012.

23. Gregg SQ, Robinson AR and Niedernhofer LJ: Physiological consequences of defects in ERCC1-XPF DNA repair enndonuclease. DNA Repair (Amst) 10: 781-791, 2011.

24. Vaezi A, Feldman CH and Niedernhofer LJ: ERCC1 and XRCC1 as biomarkers for lung and head and neck cancer. Pharmgenomics Pers Med 4: 47-63, 2011.

25. Przybylowska-Sygut K, Stanczyk M, Kusinska R, Kordek R and Majsterek I: Association of the Arg194Trp and the Arg399Gln polymorphisms of the XRCC1 gene with risk occurrence and the response to adjuvant therapy among Polish women with breast cancer. Clin Breast Cancer 13: 61-68, 2013.

26. Xu W, Wang S, Chen Q, Zhang Y, Ni P, Wu X, Zhang J, Qiang F, Li A, Røe OD, et al: TXNL1-XRCC1 pathway regulates cisplatin-induced cell death and contributes to resistance in human gastric cancer. Cell Death Dis 5: e1055, 2014.

27. Chen J, Zhao QW, Shi GM and Wang LR: XRCC1 Arg399Gln and clinical outcome of platinum-based treatment for advanced non-small cell lung cancer: A meta-analysis in 17 studies. J Zhejiang Univ Sci B 13: 875-883, 2012.

28. Yang Y and Xian L: The association between the ERCC1/2 polymorphisms and the clinical outcomes of the platinum-based chemotherapy in non-small cell lung cancer (NSCLC): A systematic review and meta-analysis. Tumour Biol 35: 2905-2921, 2014.

29. Zaanan A, Dalban C, Emile JF, Blons H, Fléjou JF, Goumard C, Istanbullu M, Calmel C, Alhazmi K, Validire P, et al: ERCC1, XRCC1 and GSTP1 single nucleotide polymorphisms and survival of patients with colon cancer receiving Oxaliplatin-based adjuvant chemotherapy. J Cancer 5: 425-432, 2014.

30. Rice TW, Blackstone EH and Rusch VW: 7th edition of the AJCC Cancer Staging Manual: Esophagus and esophagogastric Junction. Ann Surg Oncol 17: 1721-1724, 2010.

31. Livak KJ and Schmittgen TD: Analysis of relative gene expression data using real-time quantitative PCR and the 2(-Delta Delta C(T)) Method. Methods 25: 402-408, 2001.

32. Berger AC, Farma J, Scott WJ, Freedman G, Weiner L, Cheng JD, Wang $\mathrm{H}$ and Goldberg $\mathrm{M}$ : Complete response to neoadjuvant chemoradiotherapy in esophageal carcinoma is associated with significantly improved survival. J Clin Oncol 23: 4330-4337, 2005.

33. Urba SG, Orringer MB, Turrisi A, Iannettoni M, Forastiere A and Strawderman M: Randomized trial of preoperative chemoradiation versus surgery alone in patients with locoregional esophageal carcinoma. J Clin Oncol 19: 305-313, 2001. 
34. Eisenhauer EA, Therasse P, Bogaerts J, Schwartz LH, Sargent D, Ford R, Dancey J, Arbuck S, Gwyther S, Mooney M, et al: New response evaluation criteria in solid tumors: Revised RECIST guideline (version 1.1). Eur J Cancer 45: 228-247, 2009.

35. Yu X, Xiao H, Zhao B, Zhang X and Wang G: DNA repair gene ERCC1 C118T polymorphism predicts sensitivity of recurrent esophageal cancer to radiochemotherapy in a Chinese population. Thorac Cancer 6: 741-748, 2015.

36. Yoon HH and Forastiere AA: Locally advanced esophageal adenocarcinoma: Current standards and molecular predictors of outcome. Future Oncol 4: 413-425, 2008.

37. Cornetta T, Festa F, Testa A and Cozzi R: DNA damage repair and genetic polymorphisms: Assessment of individual sensitivity and repair capacity. Int J Radiat Oncol Biol Phys 66: 537-545, 2006.

38. Wu X, Gu J, Wu TT, Swisher SG, Liao Z, Correa AM, Liu J, Etzel CJ, Amos CI, Huang M, et al: Genetic variatitions in radiation and chemotherapy drug action pathways predict clinical outcomes in esophageal cancer. J Clin Oncol 24: 3789-3798, 2006.

39. Yoon HH, Catalano PJ, Murphy KM, Skaar TC, Philips S Powell M, Montgomery EA, Hafez MJ, Offer SM, Liu G, et al: Genetic variation in DNA-repair pathways and response to radiochemotherapy in esophageal adenocarcinoma: A retrospective cohort study of the eastern cooperative oncology group. BMC Cancer 11: 176, 2011.

40. Croteau DL, Peng Y and Van Houten B: DNA repair gets physica: Mapping all XPA-binding site on ERCC1. DNA Repair (Amst) 7: 819-826, 2008

41. Orelli B, McClendon TB, Tsodikov OV, Ellenberger T, Niedernhofer LJ and Schärer OD: The XPA-binding domain of ERCC1 is required for nucleotide excision repair but not other DNA repair pathways. J Biol Chem 285: 3705-3712, 2010.

42. Risom L,Møller P, Vogel U,Kristjansen PE and Loft S: X-ray induced oxidstive stress: DNA damage and gene expression of ERCC1 and HOGG1 in mouse lung. Free Redic Res 37: 957-966, 2003.
43. Ryu JS, Hong YC, Han HS, Lee JE, Kim S, Park YM, Kim YC and Hwang TS: Association between polymorphisms of ERCC1 and XPD and survival in non-small-cell lung cancer patients treated with cisplatin combination chemotherapy. Lung Cancer 44: 311-316, 2004.

44. Su D, Ma S, Liu P, Jiang Z, Lv W, Zhang Y, Deng Q, Smith S and $\mathrm{Yu} \mathrm{H}$ : Genetic polymorphisms and treatment response in advanced non-small cell lung cancer. Lung Cancer 56: 281-288, 2007.

45. Zhou C, Ren S, Zhou S, Zhang L, Su C, Zhang Z, Deng Q and Zhang J: Predictive effects of ERCCl and XRCC3 SNP on efficacy of platinum-based chemotherapy in advanced NSCLC patients. Jpn J Clin Oncol 40: 954-960, 2010

46. Warnecke-Eberz U, Vallböhmer D, Alakus H, Kütting F, Lurje G, Bollschweiler E, Wienand-Dorweiler A, Drebber U, Hölscher AH and Metzger R: ERCC1 and XRCC1 gene polymorphisms predict response to neoadjuvant radiochemotherapy in esophageal cancer. J Gastrointest Surg 13: 1411-1421, 2009.

47. Ajani JA, D'Amico TA, Almhanna K, Bentrem DJ, Besh S, Chao J, Das P, Denlinger C, Fanta P, Fuchs CS, et al: Esophageal and esophagogastric junction cancers, version 1.2015. J Natl Compr Canc Netw 13: 194-227, 2015.

48. Alexander BM, Wang XZ, Niemierko A, Weaver DT, Mak RH, Roof KS, Fidias P, Wain J and Choi NC: DNA repair biomarkers predict response to neoadjuvant chemoradiotherapy in esophageal cancer. Int J Radiat Oncol Biol Phys 83: 164-171, 2012.

49. Chen PC, Chen YC, Lai LC, Tsai MH, Chen SK, Yang PW, Lee YC, Hsiao CK, Lee JM and Chuang EY: Use of germline polymorphisms in predicting concurrent chemoradiotherapy response in esophageal cancer. Int J Radiat Oncol Biol Phys 82: 1996-2003, 2012

50. Pan JY, Ajani JA, Gu J, Gong Y, Qin A, Hung M, Wu X and Izzo JG: Association of Aurora-A (STK15) kinase polymorphisms with clinical outcome of esophageal cancer treated with preoperative chemoradiation. Cancer 118: 4346-4353, 2012. 